\title{
Comparative study between duplex ultrasound and 160-multidetectors CT angiography in assessment of chronic lower limb ischemia
}

\author{
Ahmed I. Gamal El Dein ${ }^{1}$, Ahmed E. Ebeed ${ }^{1}$, Hala M. Ahmed ${ }^{1}$ and Ahmed Abdel Khalek Abdel Razek ${ }^{2 *}$
}

\begin{abstract}
Purpose of the study: This study is aiming to evaluate the role of duplex ultrasonography in comparison with multidetector computed tomography angiography (MDCT) angiography in the assessment of lower limb ischemia.

The context: The study group includes 54 patients with unilateral or bilateral chronic lower limb ischemic disease — who have come to the Department of Radiology at Aswan University Hospital for CT angiography —and Doppler ultrasonography (US) was done for comparison. Out of the 54 patients, 6 were asymptomatic (Fontain's stage 1), 16 had intermittent claudication when walking more than $200 \mathrm{~m}$ (Fontain's stage 2a), 10 had intermittent claudication when walking more than 200 m (Fontain's stage 2b), 10 had rest pain (Fontain's stage 3), and 12 had trophic changes, ulcers, or gangrene (Fontain's stage 4).

Results: The study involved 54 patients, 24 men (44.4\%) and 30 women (55.6\%). They were between 33 and 75.0 years with mean 59.56 years and standard deviation \pm 10.3 . Out of them, there were 4 patients who had aboveknee amputation of one leg. There were 34 patients who are chronic smokers 63.0\%, 40 had diabetes $74.1 \%, 26$ had hypertension $48.1 \%$, and 4 are cardiac $7.4 \%$. There was good reliability and agreement between $C T$ and Doppler techniques with significant kappa agreement in all measurements. As regards the external iliac artery, we found that the kappa agreement was 0.87 ; common femoral artery, kappa agreement was 0.88 ; superficial femoral artery, kappa agreement was 0.82 at the upper third, 0.76 at the middle third, and 0.86 at the lower third; popliteal artery, kappa agreement was 0.87; peroneal artery, kappa agreement was 0.88; posterior tibial artery, kappa agreement was 0.93; and anterior tibial artery, kappa agreement was 0.88 .
\end{abstract}

Conclusion: Both MDCT angiography and duplex US have a good predictive value of chronic lower limb ischemia, but the combination of them has better diagnostic accuracy.

Keywords: Chronic lower limb ischemia, Duplex ultrasound, Multidetector computed tomography angiography

\section{Background}

Systemic atherosclerosis is a condition which progresses with age and decreases quality of life and life expectancy. Lower extremity peripheral arterial disease (PAD) is a common manifestation of systemic atherosclerosis in the elderly $[1,2]$. Peripheral arterial disease (PAD) is the most common condition affecting the arteries of the lower extremity.

\footnotetext{
*Correspondence: aarazek1@gmail.com; arazek@mans.edu.eg ${ }^{2}$ Department of Diagnostic Radiology, Faculty of Medicine, Mansoura University, Mansoura City, Egypt

Full list of author information is available at the end of the article
}

Compromise of arterial flow due to the stenosis and occlusions can result in limb ischemia and is defined as any pathologic process causing obstruction to the blood flow in the arteries, exclusive of the coronary and cerebral vascular beds. These individuals have a two- to fourfold higher risk of coronary heart disease and stroke [3, 4]. Peripheral arterial disease affects a large segment of the adult population. Less than $20 \%$ of patients with peripheral arterial disease have typical symptoms of intermittent claudication, whereas another third have atypical exertional leg symptoms [5]. Management strategies are governed by the 
severity of the disease. Imaging is necessary for planning the interventions in patients with lower extremity peripheral arterial disease $[6,7]$.

Non-invasive imaging modalities, including duplex ultrasonography, multidetector computed tomography angiography (MDCTA), and magnetic resonance angiography (MRA), are available for grading lower extremity arterial disease. Duplex ultrasonography has a high specificity of $95 \%$ and a somewhat lower sensitivity of $88 \%$ for detecting hemodynamically significant lesions (>50\% stenosis or occlusion) [8]. Computed tomography angiography is increasingly attractive due to the rapid technical developments. Shorter acquisition times, thinner slices, higher spatial resolution, and improvement of multidetector computed tomographic (CT) scanners enable scanning of the whole vascular tree in a limited period with a decreasing (but still substantial) amount of contrast medium [9]. An angiographic scoring system, named the ANGIO score, was developed by a team of clinicians and scientists specializing in vascular disease. This system was designed to be usable with both CT angiography (CTA) and conventional angiography as a global languish [10]. The arteries were scored 0 , 1, or 2 according to the degree of stenosis or occlusion: 0 , no stenosis or stenosis below 50\%; 1 , non-occlusive stenosis of at least 50\%; and 2, complete occlusion of the artery [11]. Owing to the limited spatial resolution, the infrapopliteal arteries were scored only 0 or 2 for the reproducibility assessment, according to the presence or absence of complete occlusion, and were assessed along their course, proximal to the ankle joint. Values for all arteries from both lower limbs were added to produce an overall score for the patient. More severe PAD was expected to result in a higher ANGIO score [11].

Optimization of intravenous contrast with blood flow and CT scanning gives higher spatial resolution and coverage of more than $120 \mathrm{~cm}$ [12, 13]. Many display formats have been developed and may be used, including multiplanar reformation, maximum intensity projection, surface-shaded display, and, most recently, volume rendering [14]. Mingjie and Yang [15] proved that PSVst/PSVdistal has higher sensitivity, specificity, and accuracy than PSVst/PSVpro. Lower limb arterial disease is an important cause of morbidity in middle-aged and the elderly. The atheromatous narrowing or occlusion of an artery or arteries of the leg commonly causes it. It may be symptomatic causing intermittent claudication, ischemic rest pain, ulceration, and gangrene [16]. Management strategies differ for patients with lower limb arterial disease. Patients with intermittent claudication are often managed conservatively, while patients with limb-threatening ischemia are treated with angioplasty, surgical revascularization, or amputation $[17,18]$.

This study is aiming to evaluate the role of duplex ultrasonography in comparison with MDCT angiography in the assessment of lower limb ischemia.

\section{Patients and methods}

The study group includes 54 patients with chronic lower limb ischemic disease, who have come to the Department of Radiology at Aswan University Hospital for CT angiography.

\section{Inclusion criteria}

The following are the inclusion criteria:

- For any age and both gender

- Patient presented with clinically diagnosed/ suspected lower limb peripheral ischemic disease

- Patient-related factors including body habitus, body size and shape, co-morbidities, history of neurological disease, diabetes, smoking, and patient preference

\section{Exclusion criteria}

The following are the exclusion criteria:

- Contraindication for MDCT

- Severe renal impairment (intolerance to iodinated contrast media)

\section{Methods}

\section{Duplex ultrasonography}

Duplex ultrasonography was done with Philips duplex ultrasound machine bandwidth frequency transducer with a range of $5-13 \mathrm{MHz}$ for the lower limb artery and 3.5 $\mathrm{MHz}$ probe for the infrarenal aorta and iliac vessels. Patients were kept fasting for at least $6 \mathrm{~h}$, to improve visualization of the aorto-iliac region. Duplex ultrasound criteria for the assessment of peripheral arterial disease patency of the vessel were determined by normal triphasic waveform pattern and color saturation, demonstrated throughout the lumen of the artery. A peak systolic velocity ratio of greater than 2 indicates a stenosis of greater than $50 \%$. In order to eliminate interobserver variation, all Doppler studies were done by the same radiologist (Fig. 1).

\section{CT angiography}

CT angiography was done with TOSHIBA 160-slice multidetector CT. Patients were placed in a supine position with the feet entering the gantry first. All multidetector row $\mathrm{CT}$ angiography examinations were performed by dedicated CT technologists. Post-processing reconstructions were performed by dedicated CT technologists, 
Cases No. (1)

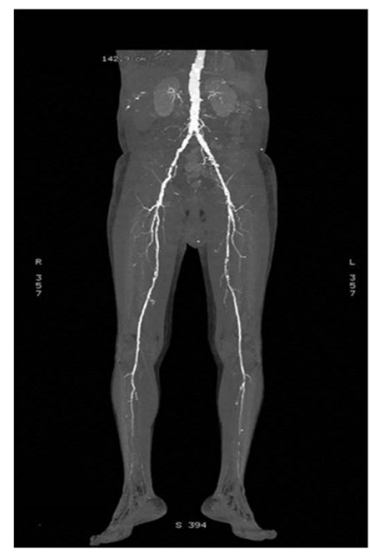

a

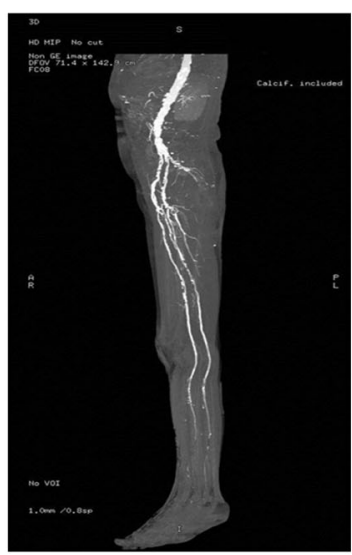

b

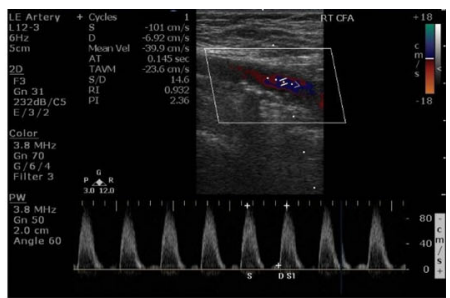

C

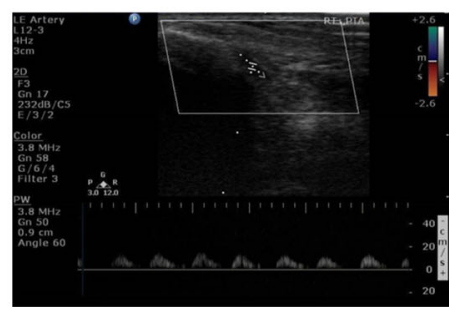

d

Fig. 1 Male patient aged 69 years, diabetic, smoker, not hypertensive, or cardiac. Color Doppler shows similar data with PSVst $100 \mathrm{~cm} / \mathrm{s}$ and PSVdist $17 \mathrm{~cm} / \mathrm{s}$ (PSVst/PSVdist < 1). a Bilateral severe atherosclerotic changes with diffuse bilateral multiple athermanous plaques with attenuated CIA, EIA, CFA, and SFA at both sides below 50\% stenosis then retained accepted opacification of POP A then attenuation of the below-knee arteries. $\mathbf{b}$ Lateral view obviously shows the atherosclerotic stenosis of EIA, CFA, and SFA at both sides with attenuated PTA and ATA after a short segment of their origin with nearly non-opacified distal parts especially the ATA. c Multiple athermanous plaques in the Rt CFA with below 50\% stenosis. $\mathbf{d}$ Attenuated Rt PTA and ATA

and images are interpreted by experienced radiologists. The images were analyzed on the basis of transverse images, MIP and VR images occlusion, calcification, plaque morphology, and collaterals.

Stenosis was graded as follows:

- Grade 1: normal vessel or mild vessel irregularities

- Grade 2: moderate arterial stenosis (> 50\% narrowing)

- Grade 3: severe arterial stenosis (<50\% narrowing)

- Grade 4: occlusion

Stenosis was scored by ANGIO scoring as follows:

- Score 0: minor or no plaque

- Score 1: stenosis $\geq 50 \%$

- Score 2: complete occlusion

\section{Image analysis}

The following vascular segments were analyzed independently for the presence of hemodynamically significant stenosis or occlusion, plaque morphology, and collaterals: infrarenal aorta, common iliac artery, external iliac artery, common femoral artery, proximal superficial femoral artery, mid-superficial femoral artery, distal superficial femoral artery, origin of deep femoral artery, popliteal artery, anterior tibial artery, posterior tibial artery, and peroneal artery.

\section{Statistical analysis}

The statistical analysis of data was done with the Statistical Package for Social Science, version 20 (SPSS Inc., Chicago, IL, USA). The interobserver agreement was expressed as a kappa ( $\kappa$ ) statistic, and the $P$ value $<0.05$ was considered to indicate statistical significance. The $K$ coefficient represents the degree of the observer agreement.

\section{Results}

The study involved 54 patients, 24 men $(44.4 \%)$ and 30 women (55.6\%). They were between 33 and 75.0 years with mean 59.56 years and standard deviation \pm 10.3. Out of them, there were 4 patients who had above-knee amputation of one leg. Out of the $54 \mathrm{pa}-$ tients, 6 were asymptomatic (Fontain's stage 1), 16 had intermittent claudication when walking more than $200 \mathrm{~m}$ (Fontain's stage 2a), 10 had intermittent claudication when walking more than $200 \mathrm{~m}$ (Fontain's stage 2b), 10 had rest pain (Fontain's stage 3), and 12 had trophic changes, ulcers, or gangrene (Fontain's stage $4)$. There were 34 patients who are chronic smokers $63.0 \%, 40$ had diabetes $74.1 \%, 26$ had hypertension $48.1 \%$, and 4 are cardiac $7.4 \%$ (Table 1 ). 
Table 1 Demographic and history of the studied group

\begin{tabular}{lll}
\hline & $n=54$ & Percent \\
\hline $\begin{array}{l}\text { Age (years), mean } \pm \\
\text { SD (min-max) }\end{array}$ & $59.56 \pm 10.3$ & \\
Sex & $(33.0-75.0)$ & \\
$\quad$ Male & & 44.4 \\
$\quad$ Female & 24 & 55.6 \\
DM & 30 & 74.1 \\
Hypertension & 40 & 48.1 \\
Cardiac & 26 & 7.4 \\
Smoking & 4 & 63.0 \\
\hline
\end{tabular}

In Table 2, as regards the external iliac artery (EIA), we found that CT diagnosed total occlusion in 3 patients, partial occlusion in 10 patients, and patent EIA in 41 patients, while US diagnosed total occlusion in 4 patients, partial occlusion in 8 patients, and patent EIA in 42 patients. Kappa agreement was significant (0.87). As regards the common femoral artery (CFA), we found that $\mathrm{CT}$ diagnosed total occlusion in 4 patients, partial occlusion in 3 patients, and patent CFA in 47 patients, while US diagnosed total occlusion in 5 patients, partial occlusion in 5 patients, and patent CFA in 44 patients. Kappa agreement was significant (0.88). As regards the superficial femoral artery (SFA), we found that in the upper third, CT diagnosed total occlusion in 4 patients, partial occlusion in 4 patients, and patent SFA in 46 patients, while US diagnosed total occlusion in 5 patients, partial occlusion in 8 patients, and patent SFA in 41 patients. Kappa agreement was significant (0.82) (Fig. 1).

In the middle third, CT diagnosed total occlusion in 2 patients, partial occlusion in 4 patients, and patent SFA in 48 patients, while US diagnosed total occlusion in 8 patients, partial occlusion in 6 patients, and patent SFA in 40 patients. Kappa agreement was significant (0.76). In the lower third, CT diagnosed total occlusion in 4 patients, partial occlusion in 2 patients, and patent SFA in 48 patients, while US diagnosed total occlusion in 4 patients, partial occlusion in 4 patients, and patent SFA in 46 patients. Kappa agreement was significant (0.86). As regards the popliteal artery (POP A), we found that CT diagnosed total occlusion in 2 patient, partial occlusion in 8 patients, and patent POP A in 44 patients, while US diagnosed total occlusion in 2 patients, partial occlusion in 10 patients, and patent POP A in 42 patients (Fig. 2). Kappa agreement was significant (0.87).

As regards peroneal $\mathrm{A}$, we found that $\mathrm{CT}$ diagnosed total occlusion in 4 patients, partial occlusion in 2 patients, and patent peroneal A in 48 patients, while US diagnosed total occlusion in 4 patients, partial occlusion in 6 patients, and patent peroneal $\mathrm{A}$ in 44 patients. Kappa agreement was significant (0.88). As regards the posterior tibial artery (PTA), we found that CT diagnosed total occlusion in 6 patients, partial occlusion in 10 patients, and patent PTA in 38 patients, while US diagnosed total occlusion in 7 patients, partial occlusion in 10 patients, and patent PTA in 37 patients (Fig. 3). Kappa agreement was significant (0.93). As regards the anterior tibial artery (ATA), we found that CT diagnosed total occlusion in 2 patient, partial occlusion in 12 patients, and patent ATA in 40 patients, while US diagnosed total occlusion in 2 patient, partial occlusion in 8 patients, and patent ATA in 44 patients. Kappa agreement was significant $(0.88)$.

\section{Discussion}

CT angiography (CTA) of the lower extremities has evolved into a robust non-invasive angiographic technique with the advent of 160- and 320-multidetector computed tomographic systems and advances in system design. CTA has displaced conventional catheter arteriography in a large range of applications and is predominantly used in the evaluation of atherosclerotic peripheral arterial occlusive disease in symptomatic patients who are candidates for intervention. Other disease entities including atheroembolism, aneurysmal disease, and arteritides including Buerger disease and Takayasu arteritis can be precisely evaluated by CTA [19].

Our study uses a quite different protocol as we used a detector configuration $160 \times 1 \mathrm{~mm}$ and 0.5 -mm-thick section while gantry rotation period is $0.3 \mathrm{~s}$. Also, they started their exams from the abdominal infrarenal aorta while we tried our best to start our exam from the arch of the aorta by butting the sure start at the arch and reducing the wait time. Ozkan et al. [20] examined the segmental distribution of atherosclerosis in 626 symptomatic patients with peripheral arterial disease. Peripheral arterial disease involved one segment in $36 \%$ of the patients, two segments in $42 \%$ of the patients, and three or more segments in $33.33 \%$ of the patients. He concluded that PAD was multisegmental in most of the cases of the study group.

Our result was quite similar as we examined $30 \mathrm{pa}$ tient, and we found that multisegmental (three or more) peripheral arterial disease definitely takes the upper hand by $73.3 \%$ while $20 \%$ of patients had two segments and only $6.67 \%$ of patients had one segment.

Osama et al. [21] studied the role of multislice CT angiography versus Doppler ultrasonography and conventional angiography in the assessment of aorto-iliac arterial disease and stated that as regards the degree of stenosis, there was an agreement between digital subtraction angiography (DSA) and multidetector row CT angiography in nine lesions (82\%), with discrepancy in two lesions (18\%). The agreement between DSA and color-coded Doppler occurred in eight lesions (73\%), 
Table 2 Reliability and agreement between $C T$ and Doppler techniques in the detection of vascular occlusion

\begin{tabular}{|c|c|c|c|c|c|}
\hline & $C T, N=54$ & Doppler, $N=54$ & Kappa agreement & $x^{2}$ & $P$ value \\
\hline \multicolumn{6}{|l|}{ EIA } \\
\hline Patent & 41 & 42 & & & \\
\hline Partial occlusion & 10 & 8 & 0.87 & 0.22 & 0.89 \\
\hline Total occlusion & 3 & 4 & & & \\
\hline \multicolumn{6}{|l|}{ CFA } \\
\hline Patent & 47 & 44 & & & \\
\hline Partial occlusion & 3 & 5 & 0.88 & 0.76 & 0.7 \\
\hline Total occlusion & 4 & 5 & & & \\
\hline \multicolumn{6}{|l|}{ SFA upper $1 / 3$} \\
\hline Patent & 46 & 41 & & & \\
\hline Partial occlusion & 4 & 8 & 0.82 & 0.9 & 0.63 \\
\hline Total occlusion & 4 & 5 & & & \\
\hline \multicolumn{6}{|l|}{ SFA middle $1 / 3$} \\
\hline Patent & 48 & 40 & & & \\
\hline Partial occlusion & 4 & 6 & 0.76 & 2.4 & 0.31 \\
\hline Total occlusion & 2 & 8 & & & \\
\hline \multicolumn{6}{|l|}{ SFA lower 1/3 } \\
\hline Patent & 48 & 46 & & & \\
\hline Partial occlusion & 2 & 4 & 0.86 & 0.36 & 0.8 \\
\hline Total occlusion & 4 & 4 & & & \\
\hline \multicolumn{6}{|l|}{ POP } \\
\hline Patent & 44 & 42 & & & \\
\hline Partial occlusion & 8 & 10 & 0.87 & 0.13 & 0.9 \\
\hline Total occlusion & 2 & 2 & & & \\
\hline \multicolumn{6}{|l|}{ Peroneal A } \\
\hline Patent & 48 & 44 & 0.88 & 1.1 & 0.58 \\
\hline Partial occlusion & 2 & 6 & & & \\
\hline Total occlusion & 4 & 4 & & & \\
\hline \multicolumn{6}{|l|}{ PTA } \\
\hline Patent & 38 & 37 & & & \\
\hline Partial occlusion & 10 & 10 & 0.93 & 0.17 & 0.9 \\
\hline Total occlusion & 6 & 7 & & & \\
\hline \multicolumn{6}{|l|}{ ATA } \\
\hline Patent & 40 & 44 & & & \\
\hline Partial occlusion & 12 & 8 & 0.88 & 0.5 & 0.8 \\
\hline Total occlusion & 2 & 2 & & & \\
\hline
\end{tabular}

while discrepancy occurred in three lesions (27\%). This discrepancy was mainly due to the ability of multidetector CT angiography to detect a small amount of contrast in the stenotic segment and the ability of the colorcoded Doppler to detect weak flow within a stenotic artery compared to digital subtraction angiography. He used a low amount of contrast material $(120-150 \mathrm{ml})$ as he had a fast scanner. His gantry rotation period was $0.5 \mathrm{~s}$. His examinations started at the level of the celiac artery. We all agreed with all these studies as we found no significant differences in the sensitivity and specificity between MDCT angiography and CCD in the detection of hemodynamically significant lesions.

With the emergence of new evidence, ACC/AHA 2005 guideline was updated in 2011 with an attempt to establish a harmony with the TASC II guideline. Following this update, Doppler ultrasonography still maintained its diagnostic value by itself or with other tools for the 
Cases No. (2)
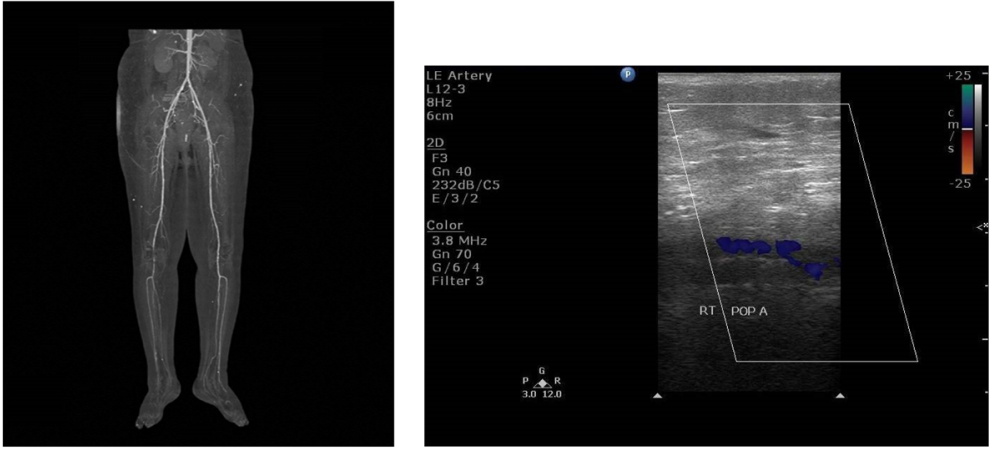

a

C

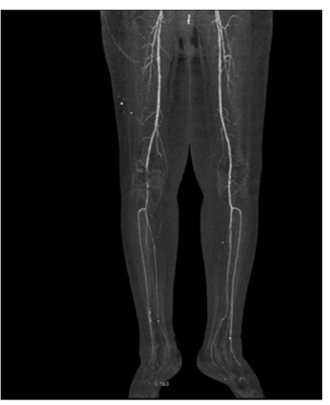

b

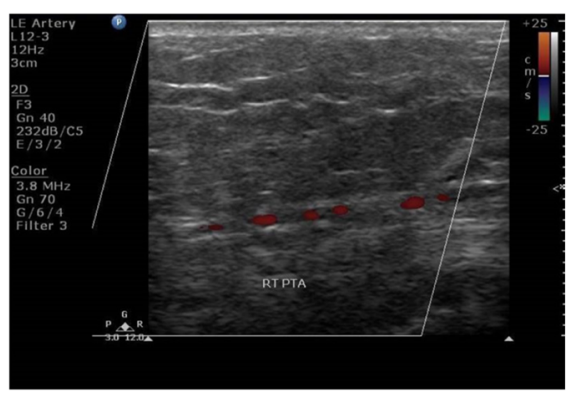

d

Fig. 2 Female patient aged 49 years, diabetic, not hypertensive, cardiac, or smoker. a Bilateral atherosclerotic changes with attenuated POP A at both sides and occluded segment at the right POP. $\mathbf{b}$ Attenuated PTA at both sides and right peroneal artery with nonopacified left one. c Completely occluded RT POP A segment. d Attenuated distal PTA

diagnosis of the PAD of the lower extremities [22]. For European countries, the first guideline of PAD was recently published by the European Society of Cardiology [23]. Similar to other guidelines, ESC guidelines recommended non-invasive Doppler ultrasonography among the first diagnostic tests to confirm and localize stenosis lesions (evidence class I, level B). To localize stenosis lesions and consider revascularization options, this latest guideline also indicated the need for either Doppler ultrasonography, CTA, or MRA (evidence class I, level A), without giving superiority to any of them. Finally, the ECS guideline recommended that any patient suggested for surgery based on any of the imaging tools should also be tested hemodynamically, which can be achieved only by Doppler arteriography.

The guideline recommendations on the management of PAD were published by the ACC Foundation in 2013. In this update, Doppler US measurements were demonstrated among the top diagnostic tests to provide an accurate assessment of lower extremity PAD location and severity (evidence class I, level A) and to provide accurate follow-up after revascularization (evidence class I, level A) [24].

Our results made us agreed with all the guidelines as we found that an experienced Doppler radiologist can make the best use of Doppler and avoid consuming time in other modalities especially when there are contraindications and also can help the vascular surgeon to make his decision in choosing intervention or medical treatment.

Bueno et al. [25] examined 1720 segments on $40 \mathrm{pa}-$ tients; the utility of Doppler US and MRA was evaluated by using CA as a reference point. When the detection of stenosis $\geq 50 \%$ was taken as the sole criterion, sensitivity and specificity values were calculated respectively to be 81.4\% and 99\% for Doppler ultrasonography and 91 and 99\% for MRA. In the same study, total occlusion sensitivity and specificity values were calculated respectively as $90 \%$ and $97 \%$ for Doppler US and $95.4 \%$ and $98 \%$ for MRA. The latter study demonstrated a relatively low sensitivity value for Doppler ultrasonography in the detection of significant stenosis in the lower limb arteries whereas the specificity value was quite acceptable.

We agreed with that as we noted that the sensitivity and specificity of the Doppler US are quite lower than CT angiography, but it is acceptable especially as we already stated that we can make use of Doppler to save time in critical cases and in cases where CT angiography is contraindicated. CT angiography has the advantages of being minimally invasive, requiring only a reasonable 


\section{Cases No. (3)}

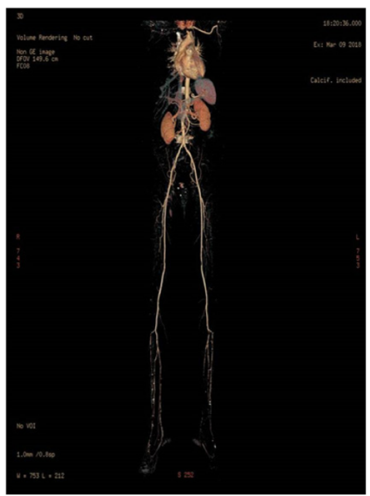

a

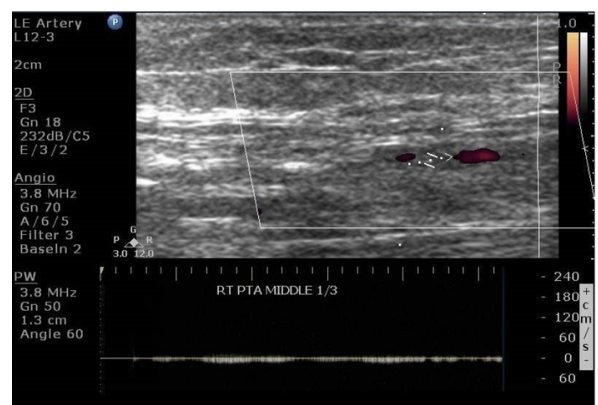

C
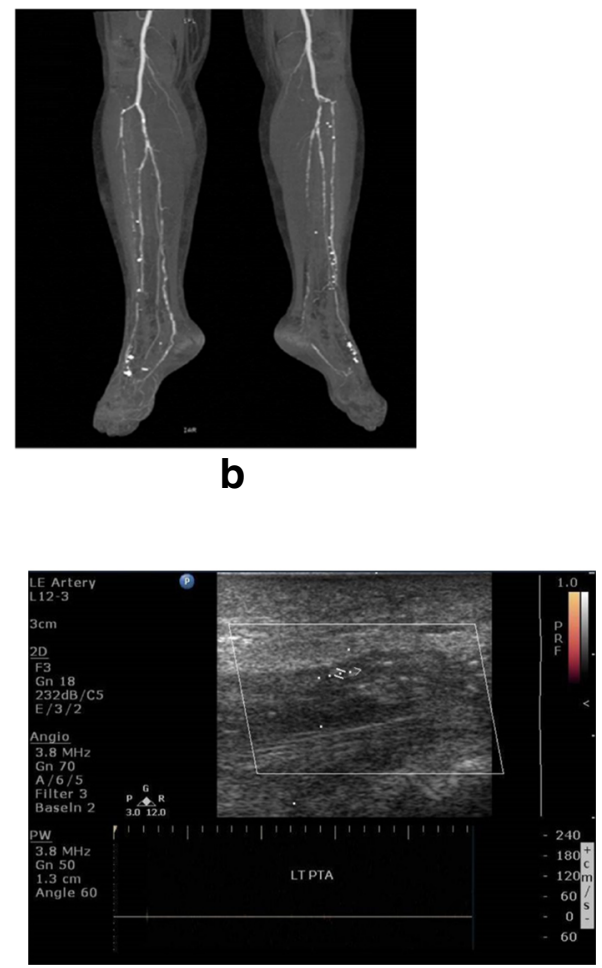

d

Fig. 3 Female patient aged 57 years, diabetic, not hypertensive, cardiac, or smoker. a Bilateral below-knee intermittent opacification. b Multiple athermanous plaques below the knee that cause stenosis but less than $50 \%$. c Attenuated right side PTA with weak venous-like waveform. $\mathbf{d}$ Attenuated left side PTA with multiple athermanous plaques

amount of the intravenous contrast and imaging surrounding soft tissues, fast, accurate, and safe and has the advantage of using MIP and 3D images for cases of peripheral vascular diseases for diagnosis, for grading, and for preoperative assessment of lower limb arterial disease. US is also a great non-invasive, fast, accurate, safe, and readily available tool for the assessment of lower limb arterial disease. It has an advantage over MDCT angiography that it provides us with hemodynamic data proximal, distal, and at the site of obstruction [26-29].

\section{Conclusion}

Both MDCT angiography and duplex US have a good predictive value of chronic lower limb ischemia, but the combination of them has a better diagnostic accuracy. We can make use of the new Doppler indices like PSV stenosis/PSVdistal that make any mildly experienced radiologist have the ability to get appreciable information from the Doppler.

\section{Acknowledgements}

All thanks to my professors who helped a lot in the study to be completed, all members of Aswan University Radiology Department, and my family who always supports me.

\section{Authors' contributions}

AG carried out the Doppler US, reconstructed the CT angiography studies, participated in the sequence alignment, and drafted the manuscript. HM helped in the data collection and study examinations and participated in the sequence alignment. AE participated in the design of the study and performed the statistical analysis. AR conceived the study, participated in its design and coordination, and helped to draft the manuscript. All authors read and approved the final manuscript.

\section{Funding}

No funding was received.

Availability of data and materials

All data are available from all authors and at both Aswan University Library and Alexandria Library.

Ethics approval and consent to participate Not applicable.

\section{Consent for publication}

Not applicable.

\section{Competing interests}

The authors declare that they have no competing interests.

\section{Author details}

'Department of Diagnostic Radiology, Faculty of Medicine, Aswan University, Tingar, Egypt. ${ }^{2}$ Department of Diagnostic Radiology, Faculty of Medicine, Mansoura University, Mansoura City, Egypt. 
Received: 14 June 2019 Accepted: 16 July 2019

Published online: 02 September 2019

\section{References}

1. Abdel Razek AA, Denewer AT, Hegazy MA et al (2014) Role of computed tomography angiography in the diagnosis of vascular stenosis in head and neck microvascular free flap reconstruction. Int J Oral Maxillofac Surg 43: 811-815

2. Algazzar MA, Elzawawi MS, Alhawary KE et al (2014) Role of multi-detector computed tomography angiography in the evaluation of lower limb ischemia. Int J of Med Imaging. 2(5):125-130

3. Kandasamy G, Maithrayee A, Kailasanathan N (2015) Lower limb arteries assessed with Doppler angiography. a prospective comparative study with multi detector CT angiography. Inter J Latest Res Sci Technol 4(6):70-83

4. Shirol RJ, Shetty A, Chethan TK (2015) Role of MDCT in evaluation of peripheral vascular disease of the lower limb arteries and comparison with colour Doppler. J Evol Med Dental Sci 4(54):9336-9346

5. Kasapis C, Gurm HS (2009) Current approach to the diagnosis and treatment of femoral popliteal arterial disease. A Systematic Review. Curr Cardiol Rev 5(4):296-311

6. Abdel Razek AAK, Elrakhawy MM, Yossof MM et al (2018) Inter-observer agreement of the Coronary Artery Disease Reporting and Data System (CAD-RADS ${ }^{\mathrm{TM}}$ ) in patients with stable chest pain. Pol J Radiol 83:e151-e159

7. Collins R, Burch J, Cranny G et al (2007) Duplex ultrasonography, magnetic resonance angiography, and computed tomography angiography for diagnosis and assessment of symptomatic lower limb peripheral arterial disease. A Systematic Review. BMJ 334:1257-1261

8. Met R, Bipat $\mathrm{S}$, Legemate DA et al (2009) Diagnostic performance of computed tomography angiography in peripheral arterial disease. A systematic review and metaanalysis. JAMA 301(4):415-424

9. Laswed T, Rizzo E, Guntern D et al (2008) Assessment of occlusive arterial disease of abdominal aorta and lower extremities arteries: value of multidetector $C T$ angiography using an adaptive acquisition method. Eur Radiol 18(2):263-272

10. Razek AA, Gaballa G, Megahed AS et al (2013) Time resolved imaging of contrast kinetics (TRICKS) MR angiography of arteriovenous malformations of head and neck. Eur J Radiol 82:1885-1891

11. Keeling A, Carroll T, McDermott M et al (2017) Clinical correlates of size and number of collateral vessels in peripheral artery disease. Vasc Med 4:223-230

12. Ota $\mathrm{H}$, Takase $\mathrm{K}$, Igarashi $\mathrm{K}$ et al (2004) MDCT compared with digital subtraction angiography for assessment of lower extremity arterial occlusive disease: importance of reviewing cross-sectional images. AJR Am J Roentgenol. 182(1):201-209

13. Chidambaram PK, Swaminathan RK, Ganesan P et al (2016) Segmental comparison of peripheral arteries by Doppler ultrasound and $C T$ angiography. J Clin Diagn Res 10(2):12-16

14. Visser K, Kock MM, Kuntz KM et al (2003) Cost effectiveness targets for multi-detector row CT angiography in the work-up of patients with intermittent claudication. Radiology 227:647-656

15. Mingjie G, Yang H (2018) Optimal ultrasound criteria for grading stenosis of the superficial femoral artery. Ultrasound Med Biol 44(2):350-358

16. Beard J (2000) Chronic lower limb ischaemia. BMJ 320:854-857

17. Dormandy JA, Rutherford RB (2000) Management of peripheral arterial disease (PAD). Tasc Working Group. Trans Atlantic Inter-Society Consensus (TASC). J Vasc Surg 31:1-296

18. Abdel Razek A, Ashmalla G, Samir S (2017) Clinical value of classification of venous malformations with contrast enhanced MR angiography. Phlebology 32:628-633

19. Foley WD, Stonely T (2010) CT angiography of the lower extremities. Radiol Clin North Am Mar 48(2):367-396

20. Ozkan U, Oguzkurt L, Tercan F (2009) Atherosclerotic risk factors and segmental distribution in symptomatic peripheral artery disease. J Vasc Interv Radiol Apr 20(4):437-441

21. Osama A, Zaytoun H, Soliman H (2012) Role of multi-slice CT angiography versus Doppler ultrasonography and conventional angiography in assessment of aorto-iliac arterial disease. Egypt J Radiol Nuclear Med

22. Creager MA, Belkin M, Bluth El et al (2012) 2012 ACCF/ AHA/ ACR/ SCAl/ SIR/STS/ SVM/SVN/SVS key data elements and definitions for peripheral atherosclerotic vascular disease: a report of the American College of Cardiology Foundation/American Heart Association Task Force on Clinical
Data Standards (Writing Committee to develop clinical data standards for peripheral atheroscleroticvascular disease). Circulation 125:395-467

23. Tendera M, Aboyans V, Bartelink ML et al (2011) ESC Guidelines on the diagnosis and treatment of peripheral artery diseases: document covering atherosclerotic disease of extracranial carotid and vertebral, mesenteric, renal, upper and lower extremity arteries: the Task Force on the Diagnosis and Treatment of Peripheral Artery Diseases of the European Society of Cardiology (ESC). Eur Heart J 32:2851-2906

24. Anderson $J \mathrm{~L}$, Halperin $\mathrm{J}$, Albert $\mathrm{N}$ et al (2013) Management of patients with peripheral artery disease (compilation of 2005 and 2011 ACCF/AHA guideline recommendations): a report of the American College of Cardiology Foundation/American Heart Association Task Force on Practice Guidelines. J Am Coll Cardiol 61:1555-1570

25. Bueno A, Acín F, Cañibano C et al (2010) Diagnostic accuracy of contrast-enhanced magnetic resonance angiography and duplex ultrasound in patients with peripheral vascular disease. Vasc Endovascular Surg 44:576-585

26. Abdel Razek AA, Elkammary S, Elmorsy AS et al (2011) Characterization of mediastinal lymphadenopathy with diffusion-weighted imaging. Magn Reson Imaging 29:167-172

27. Sepahdari AR, Politi LS, Aakalu VK et al (2014) Diffusion-weighted imaging of orbital masses: multi-institutional data support a 2-ADC threshold model to categorize lesions as benign, malignant, or indeterminate. AJNR Am J Neuroradiol 35:170-175

28. Romeih S, Al-Sheshtawy F, Salama M et al (2012) Comparison of contrast enhanced magnetic resonance angiography with invasive cardiac catheterization for evaluation of children with pulmonary atresia. Heart Int 7:e9

29. Razek AA, Saad E, Soliman N et al (2010) Assessment of vascular disorders of the upper extremity with contrast-enhanced magnetic resonance angiography: pictorial review. Jpn J Radiol 28:87 943

\section{Publisher's Note}

Springer Nature remains neutral with regard to jurisdictional claims in published maps and institutional affiliations.

\section{Submit your manuscript to a SpringerOpen ${ }^{\circ}$ journal and benefit from:}

- Convenient online submission

Rigorous peer review

- Open access: articles freely available online

High visibility within the field

- Retaining the copyright to your article

Submit your next manuscript at $>$ springeropen.com 